\title{
AUSENCIA Y VEROSIMILITUD: SOBRE LA MIME- MIS PLATÓNICA EN CONTEXTO HISTÓRICO
}

\section{ABSENCE AND VERISIMILITUD: PLATONIC MIMESIS IN HISTORICAL CONTEXT}

\author{
Guillermo Peris Bautista ${ }^{1}$ \\ CEU-Cardenal Herrera
}

Recibido: 22-03-2018

Aceptado: 7-10-2018

Resumen: En el presente trabajo se sitúa la concepción platónica de la mímesis en su contexto histórico, explicándola como producto crítico del mismo. Así, se presenta brevemente la concepción mítico-tradicional del discurso verdadero y se extiende en la concepción parmenídea del ser como influencias conocidas ante las que Platón reacciona de diversos modos para configurar una noción de mimesis como algo metafísicamente necesario, y que permea su sistema filosófico.

Palabras clave: Platón;mimesis;ser;no-ser;Parménides;mito

\begin{abstract}
The present work places Plato's notion of mimesis within historical context and explains it as a critique of this context. The different conceptions of discourses dealing with truth known to Plato are presented (the mythical and the parmenidean, which is dealt with at more length), and explained as conceptions before which Plato reacts in order to shape his own notion of mimesis as a metaphysical necessity, a notion which permeates his philosophical system.
\end{abstract}

Key words: Plato; mimesis; being; non-being; Parménides; myth

\section{Introducción}

En su libro Platón: las palabras y las cosas, Luc Brisson defiende que Platón pretendía explicar el discurso poético como un «artificio [por el que] narradores de mitos y poeta(s) procuran hacer olvidar la ausencia efectiva de ese 
otro» ${ }^{2}$, es decir, de la musa o deidad. Para este autor, dicho rasgo sería crucial en la distinción que Platón trazaría entre el discurso lógico, o filosófico, y el discurso mítico: aquél versaría sobre lo comprobable racionalmente, mientras que éste no sólo hablaría de lo que se desconoce como si fuera verdad, sino que intentaría ocultar su desconocimiento.

La explicación de Brisson se enmarcaría en la tradición que mantendría que la filosofía nace como ruptura de las explicaciones mitológicas, con la consiguiente tendencia de esta perspectiva a configurar la tarea filosófica como algo desvinculado del ámbito artístico. Así, dichos ámbitos no solo gozarían de su propia autonomía, sino que en principio no estaría claro qué podrían aportarse mutuamente. Es el caso, sin embargo, no sólo que Platón no pretendía argumentar lo que Brisson interpreta, sino que Platón aporta una comprensión mimética potencialmente capaz de restaurar la mutua relevancia del discurso artístico y el filosófico. El presente artículo se limita explicar por qué y en qué sentido es un error atribuirle a Platón dicha intención.

Brissón parece obviar que en la investigación platónica sobre los discursos verdaderos está en juego aquello que posibilita la verdad, a saber, una estuctura metafísica subyacente. Al perder este contexto se deja de lado el hecho de que quizá el mayor reto que se le planteaba era de carácter metafísico y venía representado por la concepción parmenídea del ser. En este contexto más ámplio el concepto de «ausencia efectiva» referidas por Brisson tiene consecuencias que la metafísica platónica rechazaría de plano.

En la medida en que el término "ausencia» sugiere que la deidad sería una especie de "no ser», esto es, algo inexistente que el discurso poético procuraría ocultar, se obvia el contexto más amplio en que se enmarca la obra platónica. El sistema platónico es, desde un punto de vista arquitectónico, mimético, en tanto relación asimétrica mediante la participación entre el ser (las Ideas) y el ente concreto como instancias ontológicamente distintas. Este andamiaje es fruto de una larga investigación sobre las condiciones de un tipo de relación heredada de la tradición mítica que Platón transforma profundamente y dota de supuestos metafísicos, precisamente para impedir que haya "ausencia» en su sistema, o vacío de ser. Así, para Platón, el discurso mítico no sería un discurso inverificable filosóficamente, sino un discurso ambiguo para las exigencias discursivas de la recién iniciada disciplina filosófica. El planteamiento platónico no sólo no descarta, sino que posibilita que esto se deba a un exceso o sobreabun-

2. Brisson, L.: Platón, las palabras y los mitos. Cómo y por qué dio Platón nombre al mito. Abada editores, 2006 p.33.

Thémata. Revista de Filosofía №58 (2018) pp.: 35-48. 
dancia de presencia del eidos en el ente. En términos históricos la alternativa de Parménides es para Platón aún más contradictoria y amenazante: concierne a la posibilidad de que se trate de "nada" o "ausencia» de ser del ente que es, en cuanto es lo semejante al ser.

\section{Mímesis pre-clásica, producción y pseudés}

Para hacernos cargo de la tesitura en la que se encuentra Platón es necesario recordar qué se entendía por mímesis en época arcaica. Así

La palabra mímesis es posthomérica: no aparece ni en Homero ni en Hesiodo. $\mathrm{Su}$ etimología, tal y como afirman los lingüistas, es oscura. Es muy probable que se originara con los rituales y misterios del culto dionisiaco: en su primer significado (bastante diferente al actual) la mímesis-imitación representaba los actos de culto que realizaba un sacerdote - baile, música y canto. ${ }^{3}$

Dos ejemplos frecuentemente citados al efecto confirman lo dicho en la cita. Uno de los ejemplos que se suele citar es una detallada descripción de la llegada de Dionisio a Tracia contenida en un fragmento de la tragedia perdida de Esquilo Los Edonios. La llegada de su estatua se produce al son de música acompañada por el sonido de instrumentos que "imitan" [mimoi] el bramido del toro de modo estremecedor. ${ }^{4}$ También se cita como ejemplo un fragmento de los "himnos homéricos a Apolo», donde se dice que un grupo de doncellas coribantes saben "representar" [mimesthai] las voces de cualquier hombre, y de, literalmente, emitir el sonido de castañuelas [krembaliastun]. ${ }^{5}$

Ambos ejemplos refieren la capacidad de los agentes para emitir o producir los sonidos mencionados sin mayor análisis de lo que les capacita para ello. Traducir los términos vinculados a la mímesis como «imitar» (en el primer caso), y «representar» (en el segundo) hace posible plantear cuestiones como el grado de adecuación de lo producido con el original. Sin embargo, en los ejemplos aducidos habitualmente se refieren acciones logradas cuya condición de posibilidad no es de momento problemática. Las doncellas y los instrumentos emiten las voces y los sonidos con una eficacia no cuestionada. Parece descartable cualquier conciencia de «(di)simulación» al igual que no es claro que exista conciencia de la existencia de una obra de arte separada de su producción. En este sentido, las primeras palabras con la raíz mim- refieren un modo logrado de producir algo. Por

3. Tatarkiewicz, W.: Historia de seis ideas. Arte, belleza, forma, creatividad, mímesis, experiencia estética. Traducción de Francisco Rodríguez Martín. Tecnos, 1997 (6ª ed.), p. 301.

4. Halliwell, S.: The Aesthetics of Mimesis. Ancient Texts and Modern Problems. Princeton University Press, 2002, p. 17.

5. Ibídem., p. 18

Thémata. Revista de Filosofía $\mathrm{N}^{\circ} 58$ (2018) pp.: 35-48. 
ello es planteable pensar que los agentes de dichas acciones son tenidos por estar presentando, es decir, generando de algún modo.

Por su parte, Marcel Detienne señala que en tiempos pre-clásicos el lenguaje poético compartía con el mágico-religioso (o ritual) el carácter de ser un discurso eficaz, y apunta que uno de los términos empleados para referir esta acción era "krainein», cuyo significado es «crear» o "hacer ser» lo dicho. ${ }^{6}$ Estas observaciones confirman que se entendía que el poeta personificaba en un sentido literal, esto es, que, a través de su ejecución, se hacía literalmente presente lo aparentemente ausente. Por eso la pasividad propia de todo poeta respecto de la deidad emisora (la invocación a las musas) era un rasgo propio del discurso verdadero. La práctica arcaica se hacía bajo el supuesto de que la producción del discurso verdadero ocurre durante un tiempo de producción en el que no hay diferencia entre la fuente y el vehículo, el momento en que quien produce se convierte en medium. La inspiración poética no era una cualidad del discurso «estético» en sentido moderno, sino una cualidad «científica» del discurso (por paradójico que esto suene) porque expresa lo verdadero.

La concepción de la verdad estaba así ligada a discursos mítico-religiosos saturados de significado y por ello difíciles de interpretar. Más aún, la tradición mítica incluía a dioses engañosos, puesto que éstos, porque sabían la verdad, eran quienes estaban en posición de engañar, y de revestir el engaño de una veracidad aparente. La situación del ser humano ante el lenguaje mítico era por tanto interpretada también en términos de la fundamental ambigüedad de partida que formaba parte de la producción mimética en tanto discurso verdadero. Así, en la expresión «pseudea... etumoisin homoia» traducible por "cosas falsas que parecían verdaderas», y dicha de Ulises en la Odisea,

the ambiguity of fallacious things is clearly conveyed, for the etuma are of the same reality as the alethea and, by the same token, the pseudea, through resemblance, are founded in the alethea. However, this fundamental ambiguity, left unanalyzed in mythical thought because it consists of the same, simultaneously becomes the object of rational analysis predicated on imitation, or mimesis.....the antithetical powers Aletheia and Lethe are not contradictory: in mythical thought, opposites are complementary ${ }^{7}$

Esta manera de concebir la relación entre el ser humano y el lenguaje era la tradicional tanto para Parménides como para Platón. Como discurso que aspira a explicar la totalidad de cosas existentes (una pretensión o "rango» heredada del discurso mítico), la filosofía hará entrar en crisis los supuestos de la imitación de diversos modos. Parménides para

6. Detienne, Marcel, Masters of Truth in Archaic Greece. Zone books, 1996 pp. 70-75.

7. Ibídem, p. 86 .

Thémata. Revista de Filosofía $\mathrm{N}^{\circ} 58$ (2018) pp.: 35-48. 
negar por completo su posibilidad, y Platón para restaurar un modelo imitativo profundamente transformado a la luz del hallazgo del eléata, como solución a las consecuencias contradictorias internas a éste.

\section{Parménides y la apariencia (doxa)}

En su poema, Parménides establece convincentemente la inexistencia total de la nada, la primacía absoluta de «ser» como único fundamento de la realidad, así como los rasgos esenciales que caracterizan a este ser. Dichos rasgos esenciales o "sémata" son explicados por Cordero como «los testimonios de carácter necesario y absoluto de la presencia significada por el «estin», y de todo cuanto supone esta presencia». ${ }^{8}$ Presentados y explicados entre los versos 2 y 49 del fragmento 8, estos "testimonios"-rasgos de su presencia determinan que pensamiento y formulación deban ser como el propio ser es, a saber: a) hén o uno (v.5); b) agéneton éòn, kai anólethron estin ("siendo inengendrado es también incorruptible»), es decir, perenne (v.6); b) akíneton o inmóvil (v.37); c) homón u homogéneo (v.47). ${ }^{9}$ Es decir, éstos rasgos determinan la presencia del ser en las realidades al caso, tanto en la experiencia como en el lenguaje, bajo el bien entendido supuesto de que no cabe excluir ninguno ni disminuir su sentido. Así, el ser parmenídeo no es sólo el único fundamento posible del pensamiento, sino criterio del pensamiento, y criterio del discurso que lo formula. Propiamente, sólo hay pensamientos y discursos dignos del ser cuando los informa el ser. Lo demás es opinión (doxa) y "palabras». El ejemplo que utiliza Cordero para una formulación que cumple los rasgos del ser es la fórmula química del agua, frente a una definición del agua menos precisa y, en cierto modo, engañosa como «sustancia líquida incolora e insabora». La expresión química no está sometida a las diversas apreciaciones de sujetos cambiantes, ni a las variaciones históricas del lenguaje común, ni permite modulación alguna, reflejo de que la realidad aludida, su ser, tampoco depende de variaciones históricas. Es una formulación perenne e inmóvil, y no da cabida a ambigüedades de significado, del mismo modo que el ser solo es.

El problema entonces es saber cuál es el estatuto ontológico de lo que no cumple los rasgos del ser-arché, es decir, de la doxa parmenídea.

8. Cordero, N. L.:, Siendo, se es. La tesis de Parménides, Biblos, 2005, p.193

9. En este sentido, Jean Grondin rescata una expresión de Ernst Hoffmann para resumir el resultado del poema de Parménides, en coincidencia con Cordero: «El Poema fundaría de este modo "la unidad trinitaria» entre ser, pensamiento y discurso, claramente puesta de relieve en el texto del fragmento 6, «es justo decir (legein) y pensar (noein) que el ser es (t'eon emmenai)», [es] por sí mismo un resumen de la tesis del Poema sobre el ser».Grondin, J.: Introducción a la metafísica. Herder, 2011 p. 47

Thémata. Revista de Filosofía $\mathrm{N}^{\circ} 58$ (2018) pp.: 35-48. 
Esto es problemático porque la doxa presenta un rasgo peculiar en el eléata: se parece al ser. Con palabras de Nestor Luis Cordero, «Para Parménides nada hay más peligroso que lo verosímil, pues se parece a lo verdadero sin serlo». ${ }^{10}$

El ser parmenídeo se caracteriza por no ser similar a cosa o concepto alguno. A lo largo del poema Parménides establece y despliega las consecuencias de que «queda entonces una sola palabra del camino: que 'es'» (fragmento 8, v. 1), y que ésta palabra-concepto-instancia se distingue de la doxa en tanto ésta última es un «orden engañoso» $(8, v .52)$ por cuanto habla de un «orden cósmico probable» (8, v. 60), es decir, verosímil. Ser similar es una manera de ser «engañosa» puesto que solo es el ser. La presencia del ser no es completa en aquello que es similar a él, y por tanto aquello que se le parece (porque no cumple los sémata sólo atribuibles a él) tendría que ser no ser, siendo. Desde este punto de vista, su esfuerzo por despejar las ambigüedades imposibilita cualquier mímesis, pero a costa de incurrir en una contradicción flagrante: el parecido (atestiguado por el propio poema parmenídeo) al origen o fundamento sólo es explicable como completa ausencia de ese fundamento, esto es, equivale a ser una nada. En este sentido, el ser parmenídeo presenta un problema desde el punto de vista de la experiencia sensible, porque el problema es interno a su definición: el hecho de que el ser, por su propia esencia, no admita ambigüedad ni sentido disminuído significa que cualquier «como» que ponga en relación dos términos es un tipo de relación ajena al ser del que habla Parménides. El ser parmenídeo es lo inasequible a la alteridad y a la relación por definición.

Gorgias y su Sobre el no ser confirma de algún modo lo dicho hasta ahora porque deduce las consecuencias lógicas de la propuesta filosófica parmenídea. Su triple tesis sería imposible sin Parménides como antecedente, y de hecho es un negativo, casi punto por punto, de la tesis de Parménides según la "unidad trinitaria» de Hoffmann ${ }^{11}$ : 1) el ser no existe, 2) aunque existiera no lo conoceríamos (o no lo podríamos pensar), y 3) si existiera y lo pudiésemos pensar, no lo podríamos comunicar. Que la presencia del ser parmenídeo como realidad plena dotada de los rasgos antes mencionados es problemática en relación con buena parte de las realidades de otro orden tal y como se experimentan (por ejemplo con el pensamiento no científico u opinión, y con el lenguaje común) es algo que el propio Parménides concede en su poema. A partir de ahí Gorgias tan solo explicita el status que le competiría a estas realidades con mimbres parmenídeos, a saber, no ser o no existir, sin admitir ambigüedades ni sentido

10. Cordero, N. L.: op.cit., p. 183.

11. Ver nota 9

Thémata. Revista de Filosofía №58 (2018) pp.: 35-48. 
disminuído. En consecuencia la negación del ser se vuelve una existencia positiva, en la medida en que existe un parecido o similitud pero que sólo es interpretable en este momento histórico como pura ausencia de ser. Desde el momento en que se constata la existencia de realidades que no cumplen los rasgos "necesarios y absolutos que atestiguan la presencia del ser», no queda otra alternativa en este momento de la historia que estipular la completa ausencia de ser, existiendo. ${ }^{12}$

\section{Platón: la mímesis necesaria}

Un vistazo a los títulos de los diálogos platónicos nos cerciora de que éste no dejó de preguntarse por las condiciones de la producción entre el ámbito de la arché u orígen y lo originado por éste, hasta el punto de que casi enmarca su corpus. Podría observarse que no deja de ser significativo que la investigación platónica comienza con el Ion y la inspiración poética (problema del emisor-vehículo según la imitación tradicional), pasa por la relación entre lenguaje y referente en el Crátilo (primera mención de una mimesis como solución a esta relación concreta), la relación entre lo uno y lo múltiple mediante participación (un modo de presencia del ser) en el Parménides, y la difícil dilucidación del no-ser (junto con la cuestión de los grandes géneros del ser) en el diálogo que lleva el título del imitador por excelencia, el Sofista. El trayecto, que va desde las obras tenidas por tempranas a las más tardías, presenta determinados rivales, y una problemática: la tradición poética por un lado y el par eléata-sofista en cuanto coinciden en que impiden, para Platón, una correcta comprensión de la producción o mímesis.

Desde la perspectiva platónica, todo "saber hacer» productivo, ya sea teórico o práctico, es una actividad mimética, pero entendiendo el rasgo imitativo con un sentido distinto al tradicional. El siguiente pasaje aclara cómo, según él, la rectitud de una actividad depende la contemplación e imitación de las Formas presentadas como las verdaderas realidades.

Sócrates: ¿Y qué? Si se le rompiera la lanzadera al mismo que la hace, ¿hará otra de nuevo mirando a la lanzadera rota o hacia aquella forma a la que miraba mientras hacía la lanzadera que ha roto?

Hermógenes: Hacia aquella forma, me parece a mí.

Sócrates: ¿Con toda razón diremos, pues, que esta forma es el mismo ser de la lanzadera?

12. Para una interpretación que, en base a F. M. Cornford (Platón y Parménides, Visor, Madrid, 1989) defiende que Platón falsea la verdadera tesis de Parménides al reducirla a una comprensión monista del ser, véase Teresa Oñate y Zubia, El nacimiento de la filosofía en Grecia. Viaje al Inicio de Occidente. Dykinson, Madrid, 2004.

Thémata. Revista de Filosofía $\mathrm{N}^{\circ} 58$ (2018) pp.: 35-48. 
Hermógenes: Así me parece. ${ }^{13}$

Formulado en estos términos, el problema para Platón es que a la poesía no le corresponde ser incorporada a la estructura del saber porque no contempla lo que está más allá de los sentidos, y por ello, no puede imitar en sentido propio, sino sólo producir "a ciegas", por así decir. La poesía copia superficies o apariencias de otras instancias sensibles, pero no imita en sentido estricto porque el proceso de producción mítica no pasa por una subordinación directa a una forma identificable que garantice la orthesis o rectitud imitativa. Por ello le compete el sentido menos digno de una actividad que, a fin de cuentas, es de naturaleza imitativa. Platón describe la actividad del poeta como el que lleva a cabo copias de copias, entre otras cosas, porque es una actividad llevada a cabo sin reminiscencia, esto es, un modo de recordar lo ya contemplado.

Una cuestión relevante del texto citado es que Platón no pone el énfasis de la mímesis en la perfección del objeto acabado, sino en el proceso llevado a cabo por la contemplación de lo verdadero y en las dos instancias entre las cuales media la mayor diferencia ontológica: el objeto sensible y la forma de ese objeto. Platón jamás duda de la capacidad técnica de los pintores. A lo largo de su obra da por supuesto que son capaces de reproducir con gran destreza colores y siluetas sensibles, pero no por ello les otorga mayor valor, sino menos. Poetas o pintores pueden imitar mejor en este sentido técnico, pero su imitación carece de valor porque carece de la rectitud obtenida mediante una actitud contemplativa. Una lanzadera rota elaborada mediante contemplación de la «Forma lanzadera» es, en principio, un producto imitativo más digno de tal acción que el más logrado de los retratos obtenidos por la mera observación de lo sensible.

Esto es importante porque el concepto de imagen de Platón lleva incorporado una suerte de "pobreza ontológica» que no desdice de la imagen como ente. Más bien al contrario:

Soc.: Crátilo y la imagen de Crátilo serían realmente dos, si alguno de los dioses no reprodujera tu color y tu figura, como los pintores, sino que hiciera todas las cosas del interior tal como son las tuyas, y les diera el mismo grado de blandura y de temperatura, y les imprimiera el movimiento, el alma y la reflexión, exactamente igual a como en ti existen. (...)

Crat.: Me parece que serían dos Cratilos

Soc.: ¿Ves pues, amigo, que hay que buscar una rectitud distinta de la imagen y de las cosas que ahora mencionábamos, y que no es necesario, aun cuando le falte o se le añada algo, que deje de ser imagen? ¿O no percibes que las imágenes están muy lejos de tener los mismos caracteres que las cosas de las que son imágenes?

13. Platón, Crátilo, 389b

Thémata. Revista de Filosofía $\mathrm{N}^{\circ} 58$ (2018) pp.: 35-48. 
Crat.: Sí, lo percibo. ${ }^{14}$

A las imágenes les compete su propia rectitud constitutiva. Las imágenes son "rectas» (es decir, están bien hechas) precisamente en cuanto "están muy lejos de tener los mismos caracteres que las cosas», esto es, precisamente en cuanto que les falta o sobran rasgos del referente (sea éste una Idea o un objeto sensible). Éste es el único modo de garantizar que una palabra, una imágen pictórica, o una lanzadera no entren en una especie de competición ontológica con el original o referente. Imitar es producir un tipo de objeto que "muestra las esencias" precisamente porque posee un modo de existencia que difiere de las Formas verdaderamente existentes: no es lo que la Forma es. Su estatus de no-ser la Forma, sino un ente distinto y ontológicamente menos perfecto es un hecho al cual acompaña una virtud decisiva: la capacidad de mostrar, esto es, de ser un signo que posibilita la existencia de una relación, en principio, atestiguable. La "pobreza ontológica» de la imagen posibilita el saber y la técnica en términos de imitación. La noción de imagen, copia o signo es la auténtica novedad histórica, un concepto previamente imposibilitado tanto por el tipo de producción poética tradicional, como por el planteamiento parmenídeo.

Dicho de otro modo, lo verdaderamente crucial es que el concepto de imágen, o simil está destinada en Platón a solucionar el problema del ser-arché parmenídeo, problema muy bien explicitado por Gorgias en su triple tesis, que en términos de mímesis o producción de presencia cabría formular así: 1) la naturaleza misma del ser no prevee tendencia alguna a manifestarse en otro; 2) si lo hiciese, sólo podría manifestarse como es, con toda la plenitud de su ser, impidiendo su conocimiento científico-racional: es decir, si existiese, su modo mismo de existencia impediría conocerlo; 3) si existiese y lo supiéramos, nada de lo móvil podría comunicar su naturaleza inmóvil. En Platón, la defensa de la filosofía como ciencia racional pivotea sobre un solo problema: justificar el estado del símil como una cierta presencia del ser.

$\mathrm{Al}$ examinar la lógica que subyace a las teorías de la verdad más representativas del momento, Platón encuentra que algunas de ellas comparten el hecho de constituir lo que podríamos llamar «metafísicas de la identidad excluyente», esto es, discursos que entienden la arché como algo que exige la identidad perfecta consigo misma constitutiva del ser propio que la arché es, y por ello, su presencia participada en lo distinto de ella misma resulta excluyente para que pueda ser admitida como un tipo alternativo de realidad dotado de características diversas. Si, finalmente,

14. Ibídem, 432 b-d. Cursiva añadida.

Thémata. Revista de Filosofía $\mathrm{N}^{\circ} 58$ (2018) pp.: 35-48. 
el ser parmenídeo es criterio de cuanto es (y ésta es precisamente la situación histórica, puesto que es el primero en hablar del ser), nos enfrentamos con un fundamento de la realidad lógicamente capaz sólo de originar la nada. Si la continuidad entre Parménides y Gorgias es cierta, Platón contemplaba ante sí un fundamento de la realidad, o arché, que fracasa como origen de lo distinto de sí.

Éste es el contexto histórico más amplio que permite entender la famosa afirmación del extranjero eléata en el Sofista: «para defendernos, debemos poner a prueba el argumento del padre Parménides y obligar, a lo que no es, a que sea en cierto modo, y, recíprocamente, a lo que es, a que de cierto modo no sea». ${ }^{15}$ Recordemos que en el contexto del Sofista la afirmación está destinada a dilucidar qué es una imagen, su estatuto ontológico. La expresión crucial es "en cierto modo", algo que el ser parmenídeo, como se ha visto, no tolera. Ese "cierto modo" expresa una diferencia, no una negación del ser. La imagen es aquello que, sin cumplir los criterios específicos que hacen que el ser sea lo que es por el hecho de ser lo que él mismo es, sin embargo, también la imagen es pero de una manera diversa. Con otras palabras, la imagen sería lo parecido o similar al ser, en la medida en que éste está "en cierto modo" presente (no ausente, como Brisson pretende hacer decir a Platón) aún en lo que se le asemeja sin ser, por ello, en sentido pleno. El no-ser en sentido absoluto es descartado por Platón, coincidiendo en esto con el eléata. "No ser" sólo remite ahora a la existencia de una diferencia ontológica inconmensurable entre el orígen (ser-arché) y su copia, de modo tal que la imagen sólo existe en tanto imagen del ser, y la existencia de la imagen se convierte así no en lo que impugna la existencia del ser (como, según Platón, pretendían los sofistas), sino muy al contrario en la verificación del ser como arché u origen de lo distinto de sí que amezaba, en Parménides, con fracasar por ser internamente contradictoria. ${ }^{16}$

Interesa subrayar que dicho gesto reintroduce a sabiendas la ambigüedad perdida con Parménides en lo que respecta al factor constitutivo del ente como exigencia metafísica, esto es, para no incurrir en una definición contradictoria del ser-arché. Ambigüedad no es contradicción para Platón, sino que es propio del ente y del lenguaje mostrarse ambigüo en tanto alberga rasgos opuestos, rasgos que no obstante, y en la medida en

\section{Platón Sofista, 241d}

16. Obsérvese que en el lenguaje la expresión "no ser" no tiene otro sentido que la diferencia: "esto no es aquello" solo remite a diferentes formas de ser. "No ser" no tiene un referente propio, un algo no siendo.

Thémata. Revista de Filosofía №58 (2018) pp.: 35-48. 
que el ente es imagen, reflejo o simil del ser, no pueden ser contradictorios entre sí. ${ }^{17}$

Así, en el ámbito del discurso, la tarea de la filosofía se limita a impugnar la falsedad de un dios injusto, por contradictoria respecto del ser de los dioses, pero no a denunciar todo mito como falso porque contenga ambigüedades respecto de la naturaleza de las cosas. A lo sumo, esto último le advierte de que el mito no es territorio filosófico como producción discursiva. Pero la filosofía también se asigna a sí misma la tarea de ser guardián de todo "discurso probable» ${ }^{18}$ o mito que ella no puede producir e indaga en él, presuponiendo que dicho discurso puede contener una verdad que, dado el caso, sería tan ciertamente atribuible al ser como cierta es la ambigüedad del estado de esa verdad en la imagen, lo cual exige una dilucidación desde el ser, exactamente igual que en el caso del resto de los entes existentes. La atención a la imagen del ser-arché, como existencia diferente de éste y remisible a él por presencia del arché, se vuelve crucial en Platón como única confirmación posible del ser-arché.

Platón crea el ámbito de lo otro, de lo distinto de sí como entidad real y analizable mediante el ser de lo sígnico/semiótico permitiendo que el ser de la imagen tenga una función propedéutica de lo que supone ser esencialmente, en virtud de su parecido ontológico, es decir, en virtud de una cierta rectitud constitutiva propia de su hechura, analizable e interpretable en su ambigüedad fundamental (pues no otro es el estado del ser por participación) como signo de la hechura de la Idea original, por presencia de ésta. De hecho, abre la puerta a que la imagen sea un algo en el que habita una presencia, por definición, sobreabundante, de manera que cada una de las imágenes es objeto de una potencialidad de ser (la del eidos) que puede exigir numerosos y distintos recursos lingüísticos y discursivos para dar cuenta de ella.

En definitiva, porque la nada no existe, como Parménides estableció correctamente, aunque éste no supiera cómo articular que, por necesidad metafísica, ese mismo ser-arché, si es el único principio de lo real, necesariamente debe manifestarse en todo lo que es distinto de sí, o fracasar como arché.

17. Cuando Sócrates dice en la cita anterior que "no es necesario, aun cuando le falte o se le añada algo, que deje de ser imagen", está refiriéndose a una ambigüedad constitutiva imposible en el ámbito de la Ideas, y que es propia de lo contingente, precisamente en cuanto lo sujeto a cambio. Se trata de un modo de existencia de lo contingente que es sin embargo necesaria para afianzar la existencia de la arché como origen de lo diverso a sí misma.

18. Platón Timeo, 29d

Thémata. Revista de Filosofía $\mathrm{N}^{\circ} 58$ (2018) pp.: 35-48. 


\section{BIBLIOGRAFÍA}

Brisson, Luc.: Platón, las palabras y los mitos. Cómo y por qué dio Platón nombre al mito. Buenos Aires: Abada editores, 2006

Cordero, Nestor Luis.: Siendo, se es. La tesis de Parménides, Buenos Aires, Biblos, 2005 (con texto original y traducción del autor)

Tatarkiewicz, Wladyslaw.: Historia de seis ideas. Arte, belleza, forma, creatividad, mimesis, experiencia estética. Traducción de Francisco Rodríguez Martín. Madrid, Tecnos, 1997 ( $6^{\text {a ed.) }}$

Halliwell, Stephen.: The Aesthetics of Mimesis. Ancient Texts and Modern Problems. Princeton, Princeton University Press, 2002

Detienne, Marcel.: Masters of Truth in Archaic Greece, NY: Zone Books, 1996

Grondin, Jean.: Introducción a la metafísica, Barcelona: Herder, 2011. Havelock, Eric A.: Prefacio a Platón. Barcelona: Visor, 2005.

Platón:

-Crátilo. Madrid, Gredos, (Biblioteca Clásica, Diálogos,Vol.2) 2004 -Ion. Madrid, Gredos, (Biblioteca Clásica, Diálogos, Vol. 1) 2006

-Sofista. Madrid, Gredos, (Biblioteca Clásica, Diálogos, Vol.5) 2006

-Timeo. Madrid, Gredos, (Biblioteca Clásica, Diálogos, Vol.6) 2002. 